\title{
Costing of Malaria treatment in a rural district hospital
}

\author{
Insa Koné, Paul Marschall*, Steffen Flessa \\ University of Greifswald, Faculty of Health Care Management, Greifswald, Germany; \\ *Corresponding Author: Paul.Marschall@uni-greifswald.de
}

Received 7 January 2010; revised 18 February 2010; accepted 20 February 2010.

\begin{abstract}
Objective: It is the aim of this paper to estimate the provider's cost of treating paediatric cases of Malaria in a rural African hospital. Furthermore, we intend to give some insights into the possibilities of improving the efficiency of treating children with this disease in order to support policy makers in the resource allocation process. Methods: The cost analysis was done in the district hospital of Nouna, Burkina Faso. Based on a comprehensive cost-of-illness information system, the cost of treating paediatric Malaria in the district hospital in the year 2005 were estimated using a combination of topdown and activity-based costing. It divides the entire treatment process into a set of activities along the clinical pathway and allocates monetary values for the resource consumption to each activity. Results: The average actual provider's cost were 6.74 US\$ for a paediatric outpatient with Malaria, 61.08 US\$ for a paediatric Malaria inpatient with anaemia and, respectively 74.29 US\$ for a case of paediatric Malaria with neurological affection. $54 \%$ of the cost was due to laboratory work. This high unit cost was mainly due to a severe underutilisation of the hospital capacity. The current cost recovery rate per case was between $18 \%$ and $43 \%$. It would be between $32 \%$ and $73 \%$ if the occupancy increased to $80 \%$. Conclusion: The paper demonstrates that detailed costing is possible in a district hospital in rural Africa. The unit cost seems to be extra-ordinary high and the share of laboratory cost is tremendous. However, this is mainly due to a very strong underutilisation of the existing capacities. This fact calls for intensive efforts of the management of the institution to attract more patients by improving the quality of services and in particular the satisfaction of the patients.
\end{abstract}

Keywords: Burkina Faso; Cost Analysis; Clinical Pathway; Cost Recovery; Paediatric Malaria

\section{INTRODUCTION}

Malaria is one of the most common diseases and a major obstacle for economic and human development in sub-Saharan Africa (SSA) [1,2]. In particular children in this region suffer from high morbidity and mortality caused by Malaria [3]. For instance, in Burkina Faso in the year 2005 54.94\% of the hospitalisations of children under the age of five were due to Malaria and the disease was with $57.29 \%$ the leading cause of death of under-five-years-olds [4]. In the health district of Nouna in the North-West of Burkina Faso Hammer et al. [5] analysed the causes of mortality for children and found that Malaria was the most frequent diagnosis (42\%) in this district for the years analysed (1999 to 2003).

Although the magnitude of human suffering due to Malaria is well known and a wide range of research about Malaria prevention and effective treatment is ongoing, there is very little knowledge about the cost of treating Malaria in hospitals. Compared with the magnitude of studies on the epidemiology of Malaria in SSA, the number of studies focusing on the cost of this disease in hospitals is extremely low. Provider's cost per paediatric inpatient were estimated at 86 US\$ (user fees 43 US\$) in a tertiary hospital in Senegal for the year 1996/97 [6] and at 57 to 105 US\$ in a district hospital and 33 to 44 US\$ a sub-district hospital in Kenya for the year 1993/94 [7]. Recently, Ayieko et al. [8] estimated provider's cost of treating paediatric Malaria in district hospitals in Kenya between 47 and 75 US\$ for the year 2005 without distinction between mild and severe cases. In the Ivory Coast total user fees for a hospitalised paediatric Malaria inpatient were estimated and resulted in 15 to 40 US\$ per child [9].

The majority of studies build on a snap-shot cost analysis in the hospitals and not a routine costing system. There is an urgent need to determine the cost-of-illness of Malaria and in particular of the cost of Malaria pa- 
tients in hospitals in this region based on a professional routine cost-of-illness information system.

This paper intends to contribute to the process of filling this gap. The motivation for this research is based on the conviction that proper resource allocation and an efficient roll-back of Malaria will only be possible if we know the cost of this disease so that managers can make informed decisions. The scope of the paper is limited to paediatric Malaria in Nouna district hospital, Burkina Faso. This example was chosen because a comprehensive cost-of-illness information system was established in this district in 2003 and Malaria has been an international research subject in this region for many years. The cost-information system covers direct and indirect cost as well as cost of first-line facilities and the district hospital. The methodology of the information system and the basic costing results were described elsewhere [10, 11]. The restraint to paediatric cases seems appropriate as the majority of grown-up Malaria patients already have semi-immunity and are generally treated as outpatients in rural health centres.

For this paper we used the existing cost information system and extracted the cost of treating paediatric Malaria patients in the district hospital to calculate provider's cost per patient. Consequently, the second section of this paper describes the costing methodology based on the actual patient's pathway in Nouna district hospital. Section three presents the results and section four discusses the consequences of these results for the hospital management. The paper closes with a few conclusions.

\section{METHODOLOGY}

The methodology applied for calculating the treatment cost of paediatric Malaria patients in the district hospital of Nouna is a combination of top-down and activitybased costing.

The top-down costing methodology was first developed for commercial commodities where up to $90 \%$ of cost is variable (e.g. cost of materials) and the rest (overheads) can be allocated proportionally to the costing units. This costing methodology has also been applied to hospitals [12-14]. A common approach is to divide the total cost of the institution by the number of patient days in order to determine the cost per patient day. The cost per patient is computed by multiplying the length of stay by the average cost per patient day.

However, up to $80 \%$ of total cost of hospitals is fixed and does not vary with the number of patient days. Therefore, allocating fixed cost to the diseases and patients according to the length of stay induces a severe error. In particular, the top-down approach does not allow any judgement on the impact of increased or de- creased work load of an institution as fixed cost are proportionalised. Also, the methodology does not allow to distinguish patients with different diagnosis at the same ward and often gives only a rough picture of the real cost of a patient with a specific diagnosis.

Therefore, advanced costing methodologies have been established for the service industry and in particular for hospitals. They divide the entire treatment process into several activities or sub-processes and calculate the total cost of a particular patient or diagnosis by adding up the cost along the clinical pathway [15]. This activity-based (or bottom-up) costing has become a standard in the developed world [16-18], but it is hardly applied in hospitals of developing countries as it is quite detailed and requires a degree of precision of documentation and recording that is frequently not existing in these countries [19,20].

In a nut-shell, the top-down costing approach is faster than but not as precise as the activity-based costing. On the other hand activity-based costing requires very detailed cost information which is hardly available in developed countries and even less in developing countries. Consequently, a combination of top-down and bottom-up costing was chosen to calculate costs at a paediatric ward for the specific diagnosis Malaria with the available cost data. This mixed approach has been applied to similar problems before, e.g. [21].

The first step was the analysis of the existing costing data. The provider cost information system has been established in the hospital since 2003. As for standard step-down cost analysis cost centres were defined, with the difference, that any department directly in contact with the patient (e.g. ambulance, laboratory) was defined as final cost centre. The only overhead cost centres were laundry service and technical service. Cost for overhead cost centres were allocated to the other cost centres (e.g. administration, wards, laboratory etc.) according to the workload and added to the cost per service unit of a particular cost centre (e.g. cost per laboratory test). Intermediate cost centres were not defined as all other cost centres provided services which could be directly linked to the patient. Within each of the final cost centres a variety of products were defined, e.g. at the laboratory 44 different tests. Cost for each of them were calculated by the ingredient's approach, where the final price is the product of the quantity of inputs used and their value per unit [22,23]. This means that wherever possible cost were directly allocated to a specific laboratory test (staff costs per minute, equipment, consumption material) only overhead cost (electricity, building etc.) were divided by the total number of laboratory tests as in a top-down analysis.

The second step was the design of a standard pathway 
of paediatric Malaria cases in the hospital. For this purpose, we analysed 40 files of respective in- and outpatients of the year 2006 with Malaria as diagnosis. In addition, we interviewed the personnel in charge (physician, nursing officer, head of laboratory, drug seller, head of technical service, chauffeur, head of laundry) to triangulate the findings [24,25]. Finally, direct observation provided information of workload and material consumption of procedures (ward round, laboratory tests etc.). The fact that we chose patient files from 2006 was due to a lack of reliable files for 2005. However medical staff reassured us that there had not been major changes in treatment during this period. Based on our findings a standard pathway was developed in accordance with the guidelines for Malaria treatment for Burkina Faso [4] and of the World Health Organisation [26]. The comparison with these guidelines seemed appropriate as we suspected under-provision due to patients' financial straits. Possibly, treatment is sometimes abandoned before its time as the patient runs out of money. It was however our intention to estimate cost for a complete treatment.

The third step was to calculate the total cost per patient by summing up the cost along the clinical pathway.

In addition, total user fees were calculated. As patients have to pay fees for particular services, the total fees were calculated by adding up all user fees along the standard pathway.

The cost of treatment in rural health centres, the cost of pharmacies, private transportation and indirect cost (such as cost of food, accompanying family members, lost labour time etc.) were not considered. Drug cost within the hospital were only considered when directly associated with Malaria and its complications, e.g. anaemia. Antibiotics, vitamins and others were left aside.

Within the cost centres variable and fixed cost were distinguished (Table 1) and the cost behaviour of all cost categories was analysed. Variable cost rise proportionally with service units (e.g. any further patient) while fixed cost do not change [14,27]. Drugs, for instance, are consumed proportionally to the number of patients and can be allocated directly to a particular patient or diagnosis. On the other hand, the cost for equipment are fixed and will not increase if more patients are hospitalised. Consequently, the average fixed cost per patient will decrease with a growing occupancy as the cost are distributed among more patients (fixed cost degression).

Electricity was judged to be in parts fixed and in parts variable. On one hand, for example, the lightning needed for a 6-bed-bedroom does not depend on the number of patients occupying it (it remains the same, whether occupied by one person or by six persons). On the other
Table 1. Cost behaviour of different cost categories.

\begin{tabular}{lcc}
\hline & Fixed cost & Variable cost \\
\hline Building depreciation & $100 \%$ & \\
Consumables & & $100 \%$ \\
Electricity & $50 \%$ & $50 \%$ \\
Equipment/vehicles depreciation & $100 \%$ & \\
Fuel & & $100 \%$ \\
Pharmaceuticals & & $100 \%$ \\
Salaries and wages & $100 \%$ & \\
Technical services & $100 \%$ & \\
\hline
\end{tabular}

hand, usage of medical devices accounts for a proportional rise in electricity with any further usage.

\section{RESULTS}

Table 2 gives an overview of total cost in cost centres related to paediatric Malaria for the year 2005 [28].

Based on this data from the cost information system we estimated unit cost for the services along the standard pathway including ambulance transport from a rural health centre to the hospital, laboratory tests, a bed day at the paediatric ward, medical and nursing care per day, drugs and the administrative procedure per patient from the provider's point of view as described above.

Figure 1 demonstrates the standard pathway of a paediatric Malaria patient in Nouna hospital. Although, the clinical perception of every patient is different, the series of sub-processes in the inpatient department is quite similar for almost all patients. The patient enters the paediatric ward, either because he is referred to the hospital by a rural health centre or because the relatives (usually parents) themselves decide to bring the child directly to the hospital. If necessary the hospitals ambulance is sent to fetch the child at the rural health centre. The first resources within the hospital are consumed by the consultation at the paediatric ward including anamnesis and physical examination. At the same time, registration involves the consumption of administrative time.

Depending on the general state and the Malaria symptoms the child is either admitted or treated as an outpatient. The standard treatment of an outpatient with milder Malaria is either Sulfadoxine/Pyrimethamine or Amodiaquine and an antipyretic agent in oral form. A thick blood film/blood smear is done at the laboratory to affirm the suspected diagnosis.

If the child is hospitalised an inpatient file is opened by the nurse or the physician, and medical and nursing 


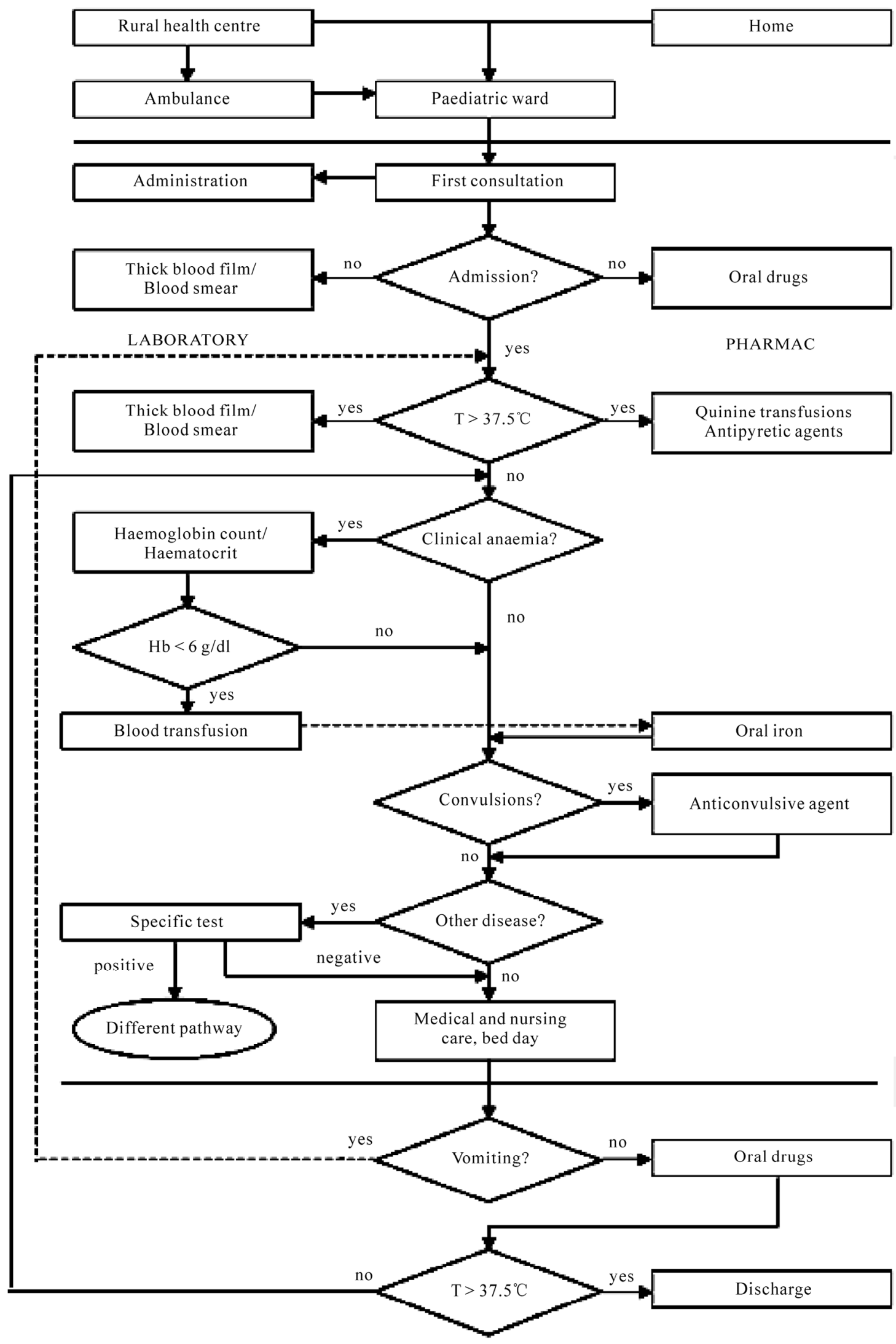

Day 1

Figure 1. Standard pathway of paediatric Malaria patients at Nouna district hospital. 
Table 2. Total cost of cost centres involved of paediatric Malaria treatment [US\$] in Nouna hospital in the year 2005.

\begin{tabular}{|c|c|c|c|c|c|c|c|c|}
\hline Department & $\begin{array}{l}\text { Building } \\
\text { depreciation }\end{array}$ & $\begin{array}{c}\text { Equipment/vehicles } \\
\text { depreciation }\end{array}$ & $\begin{array}{l}\text { Salaries \& } \\
\text { wages }\end{array}$ & Consumables & $\begin{array}{l}\text { Technical } \\
\text { services }\end{array}$ & Fuel & Pharmaceuticals & Total \\
\hline Administration & 449 & 0 & 6.404 & 1.121 & 19.720 & 4.358 & 0 & 32.050 \\
\hline Electricity & 41 & 0 & 0 & 0 & 19.582 & 0 & 0 & 19.623 \\
\hline Laboratory & 2.166 & 22.950 & 10.582 & 4.245 & 0 & 0 & 0 & 39.943 \\
\hline Laundry & 0 & 0 & 450 & 0 & 0 & 0 & 0 & 450 \\
\hline Paediatrics & 971 & 473 & 12.910 & 0 & 0 & 0 & 0 & 14.354 \\
\hline Pharmacy & 196 & 6 & 2.239 & 83 & 0 & 0 & 50.655 & 53.179 \\
\hline $\begin{array}{l}\text { Technical } \\
\text { services }\end{array}$ & 62 & 136 & 3.370 & 0 & 2.489 & 0 & 0 & 6.057 \\
\hline Transport & 0 & 0 & 0 & 0 & 0 & 0 & 0 & 0 \\
\hline Total & 3.885 & 23.565 & 35.955 & 5.449 & 41.791 & 4.358 & 50.655 & 165.658 \\
\hline
\end{tabular}

care starts. Directly connected with the examination is the preparation of blood-samples for the laboratory. Laboratory tests are asked according to clinical findings, e.g. paleness leads to a haemoglobin count/haematocrit. At the same time, parents or other accompanying relatives are instructed to buy drugs from the hospital pharmacy according to the clinical symptoms. Hospitalised Malaria cases receive intravenous anti-Malaria treatment with Quinine. The main symptoms of severe Malaria at the district hospital are anaemia ( $\mathrm{Hb}<6 \mathrm{~g} / \mathrm{dl}$ ) and convulsions. Clinic diagnosis of anaemia is confirmed by a haemoglobin count/haematocrit going along with a blood grouping. Blood transfusions are done accordingly, if the haemoglobin level is below $6 \mathrm{~g} / \mathrm{dl}$. Donors are mostly family members, thus cost occur only for blood collection, infectious screening and blood grouping. As long term treatment the children receive oral iron as substitute. Convulsions are treated with Diazepam. As Malaria symptoms are non-specific and might also be due to other infectious diseases, e.g. a gastro-enteritis or intestinal parasites, further laboratory tests can be required, e.g. blood count or white blood cell count or/and lumbar puncture. The examination of the patient's general state is repeated daily in form of the ward round and if necessary further laboratory tests are asked or/and drugs prescribed accordingly. The discharge depends on the general state of the patient. To give two important features, the child should by then be able to swallow and take an oral anti-Malaria agent and the body temperature should have dropped below $37.5^{\circ} \mathrm{C}$. In the year 2006 , the average length of stay of a paediatric inpatient with severe Malaria was 3.5 days (standard deviation 1.4) for cases with anaemia and 7.25 days (standard deviation 2.2) for cases with neurological affection. An average first con- sultation took 15 minutes.

Along the standard pathways costs were summed up assuming either an case of mild Malaria treated as an outpatient (Table 3) or the case of severe Malaria with either anaemia or neurological affection (Table 4). Cost resulted in 6.74 US\$ for a paediatric outpatient with mild Malaria and 61.08 US\$ for severe Malaria with anaemia and 74.29 US\$ for Malaria with neurological affection.

The extra-ordinary high cost of the laboratory (54\% on average) call for more analysis. A closer look reveals that the depreciation of equipment accounts for $64 \%$ of the total cost and that almost $88 \%$ of the laboratory cost are fixed cost (Figure 2). Considering the manpower it can be estimated that the number of tests performed could be increased by a factor of at least four without bringing the laboratory staff to their capacity limit. The combination of high fixed cost and low utilisation rate explains why the actual cost are quite high.

User fees are shown in Figure 4. An outpatient pays

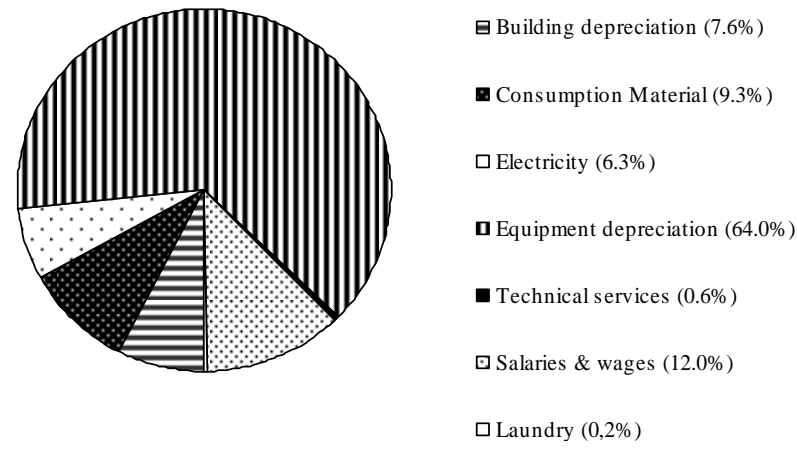

Figure 2. Distribution of laboratory cost in Nouna hospital in the year 2005. 
Table 3. Cost for standard outpatient paediatric Malaria case in Nouna hospital in the year 2005.

\begin{tabular}{lccc}
\hline & Unit cost (US\$) & Quantity per patient & Cost per patient (US\$) \\
\hline Consultation & & & $\mathbf{1 . 9 4}$ \\
Staff & 0.60 & 1 & 0.60 \\
Overhead cost & 1.34 & 1 & 1.34 \\
Laboratory & & & $\mathbf{3 . 3 6}$ \\
Thick blood film/Blood smear & 3.36 & 1 & 3.36 \\
Drugs & & & $\mathbf{0 . 6 8}$ \\
Administration & 0.76 & 1 & $\mathbf{0 . 7 6}$ \\
Total & & & $\mathbf{6 . 7 4}$ \\
\hline
\end{tabular}

Table 4. Cost for standard paediatric inpatient case with severe Malaria in Nouna hospital in the year 2005.

\begin{tabular}{|c|c|c|c|c|c|}
\hline & \multicolumn{3}{|c|}{ Anaemia } & \multicolumn{2}{|c|}{ Neurological affection } \\
\hline & Unit cost (US\$) & Quantity per patient & Cost per patient (US\$) & Quantity per patient & Cost per patient (US\$) \\
\hline Ambulance & 7.49 & 0.00 & 0.00 & 1.00 & 7.49 \\
\hline Paediatric ward & & & 13.83 & & 28.64 \\
\hline Medical care/day & 0.48 & 3.5 & 1.68 & 7.25 & 3.48 \\
\hline Nursing care/day & 1.19 & 3.5 & 4.17 & 7.25 & 8.63 \\
\hline Bed/day & 2.28 & 3.5 & 7.98 & 7.25 & 16.53 \\
\hline Laboratory & & & 41.14 & & 31.97 \\
\hline Thick blood film/Blood smear & 3.36 & 2 & 6.72 & 2 & 6.72 \\
\hline Haemoglobine count/Haematocrit & 8.00 & 1 & 8.00 & 0 & 0.00 \\
\hline Blood grouping & 4.26 & 1 & 4.26 & 0 & 0.00 \\
\hline Blood count & 4.90 & 1 & 4.90 & 1 & 4.90 \\
\hline Stool smear & 2.94 & 1 & 2.94 & 1 & 0.00 \\
\hline Blood transfusion & 14.32 & 1 & 14.32 & 0 & 0.00 \\
\hline Cerebrospinal fluid & 18.63 & 0 & 0.00 & 1 & 20.35 \\
\hline Pharmacy & & & 5.36 & & 5.43 \\
\hline Administration & & & 0.76 & & 0.76 \\
\hline Total & & & 61.08 & & 74.29 \\
\hline
\end{tabular}

2.88 US\$ and inpatients pay 16.29 US\$ in case of severe Malaria with anaemia and 13.37 US\$ in case of neurological affection. This results in a cost-recovery rate of $43 \%$ for an outpatient and $27 \%$ and $18 \%$ for the inpatients. The low cost-recovery for Malaria with neurological affection is due to the fact that the examination of cerebrospinal fluid (CSF) is done within the scope of a research project about meningitis and therefore free of charge for the patient.

\section{DISCUSSION}

This paper investigates to calculate the cost of treating paediatric Malaria based on a standard pathway and activity-based costing as an example for an appropriate method to estimate the COI in a resource-poor setting. 
Cost per case in Nouna district hospital are comparable to what was found in similar settings in Senegal and Kenya [6-8]. However, this should not mislead the management to assume that the situation in Nouna hospital is sound. Instead, there seems to be substantial wastage of resources, namely expensive devices and labour time of staff due to underutilisation.

High expenditures at the laboratory in Nouna are particularly due to high fixed cost particularly for equipment. The hospital is, in general, in a rather poor condition. However, the laboratory's building is brand new and holds up-to-date equipment not yet written off. Consequently, this department has comparably high cost. In addition, the department is strongly underutilised.

What was shown exemplarily for the laboratory is also valuable for other cost centres. If the hospital utilisation rate increased from currently $20 \%$ to $80 \%$ (NB: an occupancy between 80 and $85 \%$ is internationally seen as a professional standards [18]), the cost per inpatient would decrease to 34.59 US\$ (paediatric Malaria with aenaemia) and 42.35 US\$ (paediatric Malaria with neurological affection), whereas the cost for an outpatient visit would decrease to 3.95 US\$. Cost per bed day at the paediatric ward (including building, equipment and overhead cost) would decline by $64 \%$ and laboratory cost would decline by 54\% per patient. Figure 3 shows the cost for the standard treatment per patient against the occupancy rate.

Assuming that user fees per patient would not change in case of higher occupancy rates, cost-recovery would increase to $73 \%$ for outpatients and $47 \%$ (paediatric Malaria with anaemia) resp. 32\% (paediatric Malaria with neurological affection) for inpatients.

The costing method applied might furthermore mask higher fixed cost for medical and nursing staff. As we allocated staff cost according to the time spent for a certain patient, we do not account the additional free time caused by the lack of patients. If we divided total

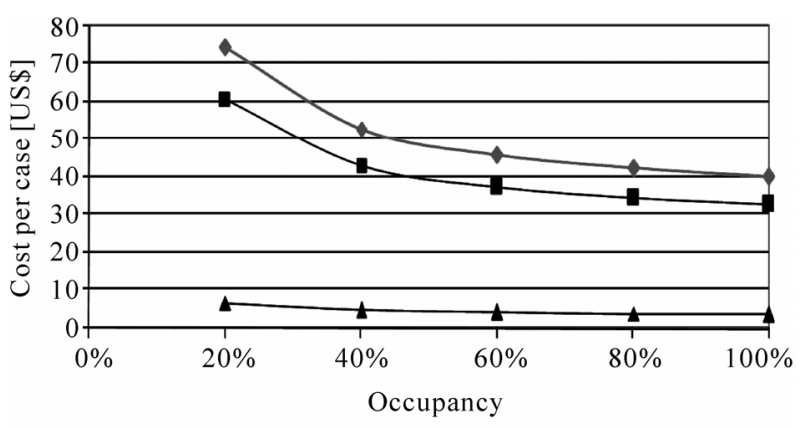

$\neg$ M. with neurological affection $-\mathbf{- M}$. with anaemia $\rightarrow-$ Mild Malaria

Figure 3. Cost for standard treatment against occupancy rate in Nouna hospital in the year 2005.

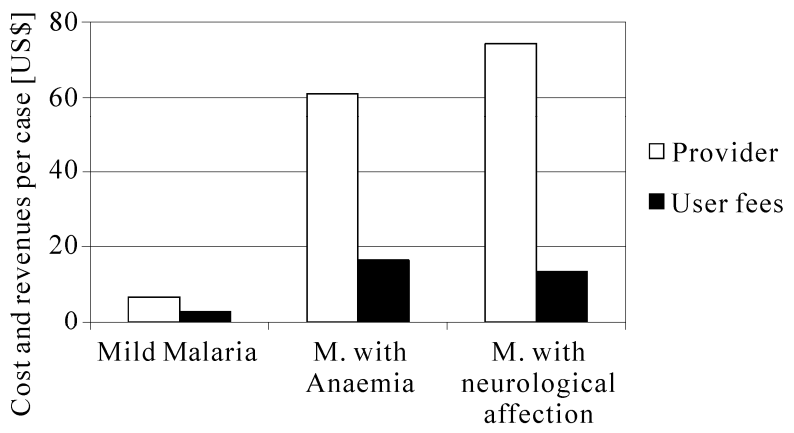

Figure 4. Provider's cost and user fees in Nouna hospital in the year 2005.

staff cost at the paediatric ward or at the laboratory by the number of patients or tests, cost per unit would be even higher.

The low occupancy rates and general underutilisation of health care in Nouna health district [29-31] and Burkina Faso as a whole [32] lead to high average cost per patient especially for staff $[11,33]$. To improve efficiency utilisation should be enhanced.

Possible reasons for low utilisation might be existing patients' dissatisfaction with the quality of health services [30,34-36] leading to a preference towards traditional healers or self-treatment. Baltussen et al. [37] found that the quality of care perceived at Nouna hospital was even worse than that of rural health centres.

Further reasons for low utilisation rates might be the distance to the health care facilities, as well as the influence of financial barriers [31,38]. Although longer distances to rural health centres can be avoided even in rural areas by appropriate planning [39] there does not seem to be an easy solution for the distance to the hospital.

User fees, on the other hand, were introduced according to the Bamako Initiative to make health care sustainable. Furthermore the correlation between better quality and increasing utilisation rates was shown by Litvack and Bodart [40] and Mariko [41] and was stronger than between abolition of user fees and utilisations rates. Thus management efforts have to focus on the quality of health care services in Nouna as elsewhere in SSA.

Our findings underline the results of other authors that a standard pathway is a useful tool not only for costing, but also to ameliorate the quality of care in cooperation with the health personnel $[24,42]$ by establishing a standardised sequence of interventions along the patient's hospital stay. Criteria should be defined under which investigations are required within predefined time-frames. Any performed investigation has a consequence for the ongoing treatment and if at a certain point the treatment does not show the expected effects alternatives are fore- 
seen. Furthermore, prefabricated patient files based on the clinical pathway could be developed, which simplify documentation. Also, total cost can be estimated already at the moment of admission and provide planning reliability to the health care provider as well as to the patient or his accompanying relatives. In Guinea-Bissau, for instance, it was shown, that a standardised protocol for the management of paediatric Malaria can lead to a decrease in mortality and average hospital stay, when going along with monitoring and a financial incentive for the staff [43].

\section{CONCLUSIONS}

Activity-based costing is an appropriate method to calculate the COI even in resource-poor settings and thus can be an important starting point to investigate inefficiencies.

Higher occupancy rates are the crucial point for a more proper resource allocation and a more efficient Malaria treatment in Nouna district hospital. Further development of the clinical pathway might be a positive incentive to improve quality of care and thereby render the hospital more attractive for the population to accentuate demand for modern healthcare. Increasing the utilisation of the district hospital would also help to make the hospital more sustainable as cost-recovery rates would considerably augment. Nevertheless, it is hardly possible that the hospital in its current configuration will break even.

A major share of total provider's cost is due to fixed cost. Increasing utilisation helps to lower average cost per case, ceteris paribus. Furthermore, unnecessary cost should also be avoided. For example before investing in new equipment for example at the laboratory, it should be verified if further devices are adequate for a district hospital in a developing country.

\section{SHORTCOMINGS}

We are aware that the suggested oral Malaria treatment changed lately to ACT (Artemisinin-based combination therapy) to control the growing resistance against antiMalaria agents [26]. This treatment option was not available at Nouna district hospital in the years 2005 and 2006. The introduction of ACT might slightly increase provider cost for drugs, but does probably not change total treatment costs substantially as drug cost stand only for a small part of total provider's cost.

It was not possible to evaluate the level of patients' unofficial payments. It is likely they do pay for better or faster treatment, especially since considerable "hidden cost" were discovered in other low-income countries [44].
On the other hand, exemption mechanisms for indigents and pupils were also not considered when calculating total user fees and cost-recovery rate.

\section{ACKNOWLEDGEMENTS}

We would like to thank the German Research Society (DFG) for funding this study as project of SFB 544. We would also like to express our gratitude towards Ali Sié, Germain Savadogo, Dimitri Poda and Athanase Pacéré for supporting data collection for the cost information data base.

\section{REFERENCES}

[1] Sachs, J. and Malaney, P. (2002) The economic and social burden of malaria. Nature, 415(6872), 680-685.

[2] Bartram, J., Lewis, K., Lenton, R. and Wright, A. (2005) Focusing on improved water and sanitation for health. Lancet, 365(9461), 810-812.

[3] Lopez, A.D., Mathers, C.D., Ezzati, M., Jamison, D.T. and Murray, C.J.L. (2006) Global and regional burden of disease and risk factors, 2001: Systematic analysis of population health data. Lancet, 367(9524), 1747-1757.

[4] Ministère de la Santé du Burkina Faso (2006) Directives nationales pour la prise en charge du paludisme au Burkina Faso. Ouagadougou.

[5] Hammer, G.P., Somé, F., Müller, O., Kynast-Wolf, G., Kouyaté, B. and Becher H. (2006) Pattern of cause-specific childhood mortality in a Malaria endemic area of Burkina Faso. Malaria Journal, 5(1), 47.

[6] Faye, O., N’Dao, O., Camara, B., Soumare, M., Dieng, T., Bah, I.B., et al. (1999) Prise en charge du paludisme grave de l'enfant dans un pays en développement: élaboration d'un protocole d'évaluation médico-économique. American Journal of Tropical Medicine and Hygiene, 5(3), 283-286.

[7] Kirigia, J.M., Snow, R.W., Fox-Rushby, J. and Mills, A. (1998) The cost of treating paediatric Malaria admissions and the potential impact of insecticide-treated mosquito nets on hospital expenditure. Tropical Medicine \& International Health, 3(2), 145-150.

[8] Ayieko, P., Akumu, A.O., Griffiths, U.K. and English, M. (2009) The economic burden of inpatient paediatric care: Household and provider costs for treatment of pneumonia, malaria and meningitis. Cost Effectiveness and Resource Allocation, 7, 3. http://www.resource-allocation. com/content/7/1/3.

[9] Couitchéré, G.L.S., Niangué-Beugré, M., Oulaï, S.M., Kouma, M., Yao, A., Atimère, Y.N., et al. (2005) Evaluation des coûts directs de la prise en charge du paludisme grave de l'enfant à l'hôpital général de Bonoua, Côte d'Ivoire. Archives of Pediatrics \& Adolescent Medicine, 12(3), 332.

[10] Flessa, S. and Kouyaté, B. (2006) Implementing a comprehensive cost information system in rural health facilities: The case of Nouna health district, Burkina Faso. Tropical Medicine \& International Health, 11(9), 14521465. 
[11] Marschall, P. and Flessa, S. (2008) Expanding access to primary care without additional budgets? A case study from Burkina Faso. The European Journal of Health Economics, 9(4), 393-403.

[12] Shepard, D.S., Hodgkin, D. and Anthony, Y.E. (2002) Analysis of hospital cost: A manual for managers. World Health Organization, HSD Programme, Geneva.

[13] Asaad, B. (2000) Krankenhäuser-spezifische Kosten- und Leistungsrechnung. Aktuelle Anwendung in Deutschland und Aufbau-sowie Übertragungsmöglichkeiten in andere Länder (am Beispiel Syrien), Göttingen.

[14] Flessa, S. and Dung, N.T. (2004) Costing of services of Vietnamese hospitals: Identifying cost in one central, two provincial and two district hospitals using a standard methodology. The International Journal of Health Planning and Management, 19(1), 63-77.

[15] Udpa, S. (1996) Activity-based costing for hospitals. Health Care Management Review, 21(3), 83-96.

[16] Asadi, M.J. and Batz, W.A. (1996) Activity-based costing for clinical paths. An example to improve clinical cost \& efficiency. International Journal of Mental Health Systems, 5(2), 1-7.

[17] Lin, B.Y., Chao, T.H., Yao Y., Tu, S.M., Wu, C.C., Chern, J.Y., et al. (2007) How can activity-based costing methodology be performed as a powerful tool to calculate cost and secure appropriate patient care? Journal of Medical Systems, 31(2), 85-90.

[18] Flessa, S. (2008) Grundzüge der Krankenhaussteuerung. Oldebourg, München.

[19] Waters, H., Abdallah, H. and Santillán, D. (2001) Application of activity-based costing (ABC) for a Peruvian NGO healthcare provider. The International Journal of Health Planning and Management, 16(1), 3-18.

[20] Hussain, H., Watersw, H., Omer, S.B., Khan, A., Baig, I.Y., Mistry, R., et al. (2006) The cost of treatment for child pneumonias and meningitis in the Northern Areas of Pakistan. The International Journal of Health Planning and Management, 21(3), 229-238.

[21] Hansen, K., Chapman, G., Chitsike, I., Kasilo, O. and Mwaluko, G. (2000) The costs of HIV/AIDS care at government hospitals in Zimbabwe. Health Policy and Planning, 15(4), 432-440.

[22] Johns, B., Baltussen, R. and Hutubessy, R. (2003) Programme cost in the economic evaluation of health interventions. Cost Effectiveness and Resource Allocation, 1, 1. http://www.resource-allocation.com/content/1/1/1

[23] Lara, A.M., Kandulu, J., Chisuwo, L., Kashoti, A., Mundy, C. and Bates, I. (2007) Laboratory cost of a hospital-based blood transfusion service in Malawi. Journal of Clinical Pathology, 60(10), 1117-1120.

[24] Campbell, H., Hotchkiss, R., Bradshaw, N. and Porteous, M. (1998) Integrated care pathways. British Medical Journal, 316(7125), 133-137.

[25] Franco, L.M., Franco, C., Kumwenda, N. and Nkhoma, W. (2003) Methods for assessing quality of provider performance in developing countries. International Journal for Quality in Health Care, 14(Suppl 1), 17-24.

[26] WHO (2006) Guidelines for the treatment of Malaria. WHO, Geneva.

[27] Lave, J.R. and Lave, L.B. (1984) Hospital cost functions. Annual Review of Public Health, 5, 193-213.

[28] Flessa, S. (2009) Costing of health care services in de- veloping countries. A prerequisite for affordability, sustainability and efficiency, Frankfurt am Main, Lang.

[29] Mugisha, F., Kouyaté, B., Gbangou, A. and Sauerborn, R. (2002) Examining out-of-pocket expenditure on health care in Nouna, Burkina Faso: Implications for health policy. Tropical Medicine \& International Health, 7(2), 187-196.

[30] Mugisha, F., Kouyaté, B., Dong, H., Chepng'eno, G.and Sauerborn, R. (2004) The two faces of enhancing utilization of health-care services: Determinants of patient initiation and retention in rural Burkina Faso. Bull World Health Organ, 82(8), 572-579.

[31] Su, T.T., Kouyaté, B. and Flessa, S. (2006) Catastrophic household expenditure for health care in a low-income society: A study from Nouna District, Burkina Faso. Bull World Health Organ, 84(1), 21-27.

[32] Makinen, M., Waters, H., Rauch, M., Almagambetova, N., Bitran, R., Gilson, L., et al. (2000) Inequalities in health care use and expenditures: Empirical data from eight developing countries and countries in transition. Bull World Health Organ, 78(1), 55-65.

[33] Krishnan, A., Arora, N.K., Pandav, C.S. and Kapoor, S.K. (2005) Cost of curative pediatric services in a public sector setting. Indian journal of paediatrics, 72(8), 657660.

[34] Krause, G., Schleiermacher, D., Borchert, M., Benzler, J., Heinmüller, R., Ouattara, K., et al. (1998) Diagnostic quality in rural health centres in Burkina Faso. Tropical Medicine \& International Health, 3(2), 100-107.

[35] Bodart, C., Servais, G., Mohamedm Y.L. and SchmidtEhry, B. (2001) The influence of health sector reform and external assistance in Burkina Faso. Health Policy Plan, 16(1), 74-86.

[36] Haddad, S., Nougtara, A. and Fournier, P. (2006) Learning from health system reforms: Lessons from Burkina Faso. Tropical Medicine \& International Health, 11(12), 1889-1897.

[37] Baltussen, R.M.P.M., Yé, Y., Haddad, S. and Sauerborn, R.S. (2002) Perceived quality of care of primary health care services in Burkina Faso. Health Policy Plan, 17(1), 42-48.

[38] Ridde, V. (2003) Fees-for-services, cost recovery, and equity in a district of Burkina Faso operating the Bamako Initiative. Bull World Health Organ, 81(7), 532-538.

[39] Cocking, C., Flessa, S. and Reinelt, G. (2006) Locating health facilities in Nouna district, Burkina Faso. In: Haasis, H-D., Kopfer, H. and Schönberger, J. Eds., Operations Research Proceedings 2005, Springer, Berlin, 431-436.

[40] Litvack, J.I. and Bodart, C. (1993) User fees plus quality equals improved access to health care: Results of a field experiment in Cameroon. Social Science \& Medicine, 37(3), 369-383.

[41] Mariko, M. (2003) Quality of care and the demand for health services in Bamako, Mali: The specific roles of structural, process, and outcome components. Social Science \& Medicine, 56(6), 1183-1196

[42] Pearson, S.D., Goulart-Fisher, D. and Lee, T.H. (1995) Critical pathways as a strategy for improving care: Problems and potential. Annals of Internal Medicine, 123(12), 941-948.

[43] Biai, S., Rodrigues, A., Gomes, M., Ribeiro, I., Sode- 
mann, M., Alves, F., et al. (2007) Reduced in-hospital mortality after improved management of children under 5 years admitted to hospital with Malaria: Randomised trial. British Medical Journal (Clinical research Ed.), 335, 862, http://www.bmj.com/cgi/content/abstract/335/7625/862

[44] Nahar, S. and Costello, A. (1999) The hidden cost of 'free' maternity care in Dhaka, Bangladesh. Health Policy Plan, 13(4), 417-422. 